\title{
Digital economy and its role in accounting
}

\author{
Zhuldyz Kupenova ${ }^{1}$,Sariya Baimukhanova ${ }^{1 *}$, Gulnar Nurgalieva ${ }^{1}$, Gulnar Zhunisova ${ }^{1}$, and \\ Aigerim Nurmukhan ${ }^{1}$
}

Al-Farabi Kazakh National University, Almaty, Kazakhstan,

\begin{abstract}
The digital economy is one of the accelerating drivers for economic growth today. In this regard, the article discusses the concept of «Digital economy», the importance of accounting and its role in the digital economy; the need for further development of theoretical and methodological provisions of accounting, state projects that have been successfully implemented in the framework of the «Digital Kazakhstan» program regarding accounting; and the transformation of accounting activities in the digitalization of the economy. The main directions of accounting modernization in the digital economy and information society are considered. Digital literacy is the knowledge and ability of a person to use information and communication technologies in their daily and professional activities. changes to the accountant's function, adding artificial intelligence to accounting operations, Robots, or programs that process data.
\end{abstract}

\section{Inroduction}

The state program «Digital Kazakhstan» was approved by the decree of the Government of the Republic of Kazakhstan No. 827 dated December 12, 2017 in order to accelerate the development of the economy of the Republic of Kazakhstan and improve the quality of life of the population, as well as create conditions for the transition of the economy to a fundamentally new trajectory - the digital economy.

The digital economy refers to an economy based on digital computing technologies, although we increasingly see this as doing business through markets based on the Internet and the world wide web. The digital economy is also sometimes referred to as the Internet economy, the new economy, or the web economy. The digital economy is increasingly intertwined with the traditional economy, making it difficult to distinguish clearly. The term «digital economy» was first mentioned in Japan by a Japanese Professor and research economist at the height of the Japanese recession of the 1990s. in the West, the term followed and was introduced in 1995 in don Tapscott's book the Digital economy: perspectives and dangers in the age of network intelligence. This was one of the first books that looked at how the Internet would change the way we do business.

According to Thomas Mesenbourg (2001), it is possible to allocate three main components of the concept of «digital economy» [1]:

\footnotetext{
* Corresponding author: bsariya@ rambler.ru
} 

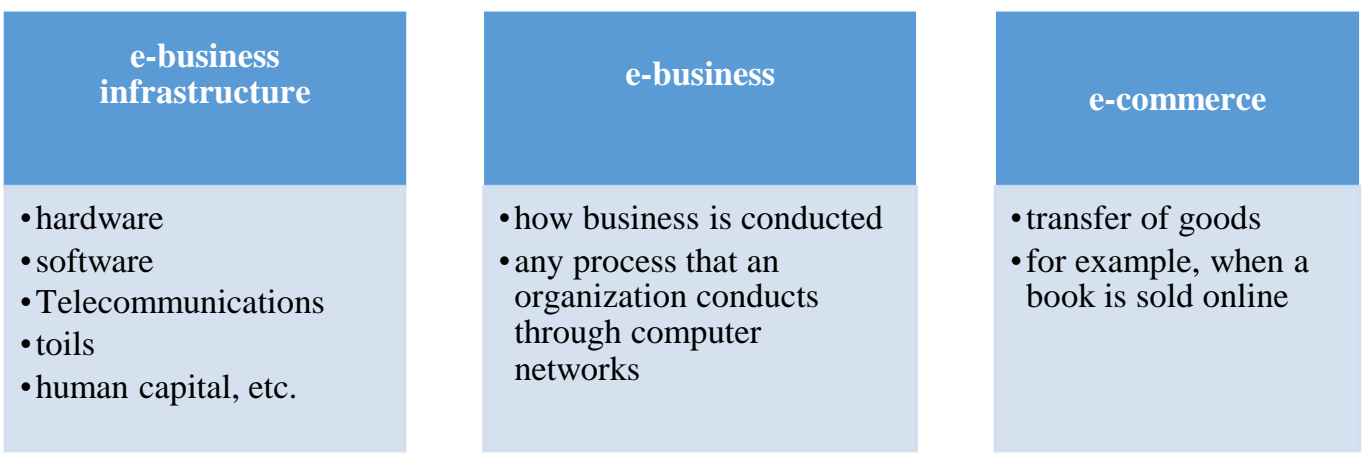

Fig.1. The basic concept of the «digital economy» Thomas Mesenbourg (2001)

In this new economy, digital network and communication infrastructures provide a global platform where people and organizations develop strategies, interact, communicate, collaborate, and search for information.

\section{Results and discussions}

The digital economy is rapidly developing all over the world. This is the single most important driver of innovation, competitiveness and growth, and it has huge potential for entrepreneurs and small and medium-sized businesses (SMEs). How companies implement digital technologies will be a key factor in their future growth. New digital trends, such as cloud computing, mobile web services, smart networks, and social networks, are radically changing the business landscape, changing the nature of work, the boundaries of businesses, and the responsibilities of business leaders. These trends contribute not only to technological innovation. They encourage innovation in business models, business networking and knowledge transfer, and access to international markets.

The program "Digital Kazakhstan" States that the effectiveness of government agencies depends on the level of automation of processes related to the implementation of daily routine operations, such as personnel, accounting, budget planning, planning and execution of public procurement, correspondence with other government agencies, and so on. In order to effectively interact with government agencies and comply with the "paper free" principles, it is planned to develop a business process management system based on the principles of cloud computing with further development into digital storage [2].

Significant changes in all spheres of public life and the transformation of the economy based on information drivers of development determine the importance of updating the information environment of the new economy, which significantly affects accounting. Issues of accounting development are of particular importance in the context of rapid development of information and communication technologies and global digitalization [3].

Such changes certainly affect the entire system of information support for socio-economic processes, in which accounting has traditionally played a significant role with its functionality of collecting, processing and providing economic information about the activities of economic entities [4].

As noted in the program "Digital Kazakhstan", we refer to the world experience, in particular, the Singapore program "SMEs Go Digital" where, for small and medium-sized businesses, entrepreneurs will have access to various it services, such as accounting, human resource management, financial analysis, and so on. 
According to the definition of the European community, the digital economy is the result of the transformational effects of new General-purpose technologies in the field of information and communication [5]. By interpreting the definitions, you can identify areas of transformation under the influence of the digital economy (Fig. 2).

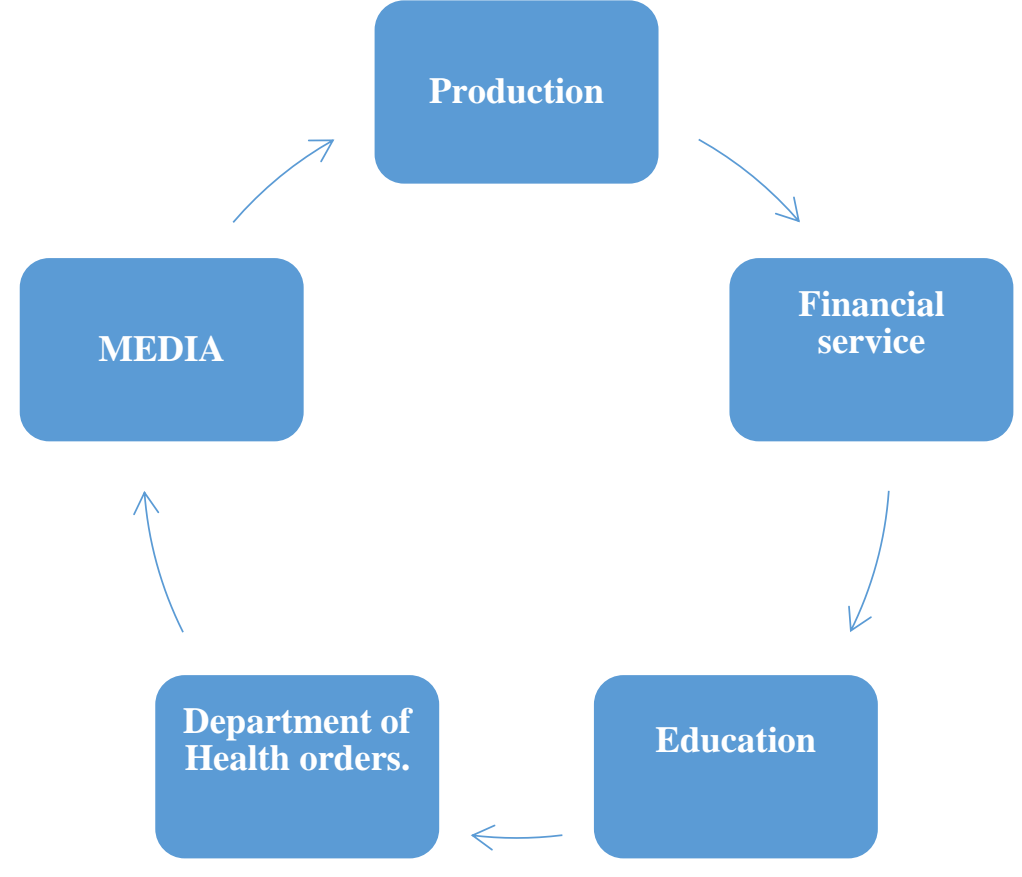

Fig.2. The field of transformation to the digital economy [6]

In this case, the accounting methodology should respond properly to the new direction of the economy. The problem of rethinking and developing the methodology for cost accounting and calculating processes and products is particularly relevant. Solving the problem is caused by the need to analyze past activities and plan for the future.

In turn, accounting is a field of activity that affects many aspects of the daily life of society. The need for further development of theoretical and methodological provisions of accounting can be seen in the works of Professor baymukhanov S. B. and many other authors of the Fatherland.

Knowledge of the theory is necessary, first of all, for those who work and solve vital problems, in particular how to make a profit and how to calculate it, and by choosing a particular methodology, an accountant or entrepreneur can increase the financial result. In order for owners, investors, administrators, government officials, etc.to understand the methods of determining financial results adequately, we need a modern theory.

At the same time, the legislation of each country takes part in determining the accounting requirements. However, the degree of influence of accounting professionals on this activity may differ significantly. For example, in the US, financial statements are prepared mainly in the interests of shareholders, in the UK - creditors, in Germany and France-the main focus of attention is the tax authorities. [7].

Many researchers believe that the main directions of transformation, in terms of improving the theory of accounting and reporting in the digital economy, are shown in Fig. 2. It is particularly possible to highlight the study of opportunities for evaluating new 
accounting objects, which are intellectual human capital, customer base, innovative products, etc. [8] It is observed that non-financial information is included in the accounting system (the quality of the client base, the state or implementation of social responsibility, the presence of economic security risks, the degree of use of energy-saving technologies, etc.). There are modern developments of new information technologies, such as cloud technologies, open technology platforms, electronic reference and information systems, and the creation of a single international format and content of financial statements in electronic form.

\begin{tabular}{l} 
expanding the scope of the organization's activities in \\
accounting \\
improving the quality and efficiency of information \\
identifying and increasing the number of new accounting \\
items \\
$\begin{array}{l}\text { development of innovative methods for evaluating new } \\
\text { accounting items } \\
\text { formation of approaches to integration of various types of } \\
\text { accounting } \\
\begin{array}{l}\text { use of domestic and foreign advanced information } \\
\text { technologies }\end{array} \\
\text { development of theoretical, methodological and applied } \\
\text { aspects of accounting development }\end{array}$ \\
\hline
\end{tabular}

Fig.3. Some areas of development of accounting methodology

It is necessary that the theoretical results be used in the development of methods and specific recommendations, the practical implementation of which will contribute to the effective implementation and development of the accounting system. In addition, the company believes that there is a need to accumulate experience in accounting and disclosure of economic information in reporting based on cardinal modifications in the field of obtaining, exchanging and processing economic information [9]

Today's digital technologies, such as blockchain, are already being interpreted as a prerequisite for a revolution in accounting methods, such as the registration system. «Instead of generating and storing individual transaction records locally, businesses will be able to record them in a unified register, creating a distributed and interconnected system of reliable accounting information," Deloitte said in a statement. "Since all records are distributed and cryptographically protected, their falsification or destruction becomes almost impossible. Bitcoin Magazine calls this a triple account» [10].

The formation of the information environment of the digital economy has an impact on the development of all the main elements of the accounting method. For example, S. F. Golov suggests developing a system of accounts, including perspective accounts, control accounts, differential accounts, accounts for non-financial information, and so on. 
Having determined the importance of accounting in the digitalization of the economy, we will focus on some Government programs that have been successfully implemented in Kazakhstan [2]:

Table 1 - State program

\begin{tabular}{|c|c|c|c|}
\hline № & Project name & Short description & implementation \\
\hline 1 & $\begin{array}{l}\text { Online cash register for } \\
\text { business }\end{array}$ & $\begin{array}{l}\text { A service that allows an entrepreneur } \\
\text { to keep financial records of their } \\
\text { business online and automatically } \\
\text { submit tax returns to regulatory } \\
\text { authorities. Previously, an } \\
\text { entrepreneur had to submit a tax return } \\
\text { to the tax Committee, work with } \\
\text { employees, which caused risks for } \\
\text { corruption. Now, when financial } \\
\text { accounting is conducted by onain and } \\
\text { all information is sent to the tax office, } \\
\text { the entrepreneur does not need to go } \\
\text { anywhere, wait for inspections. }\end{array}$ & October 2018 \\
\hline 2 & $\begin{array}{l}\text { VAT administration with the } \\
\text { use of blockchain } \\
\text { technology. }\end{array}$ & $\begin{array}{l}\text { The project was launched for this } \\
\text { purpose. To solve the problem of state } \\
\text { revenue agencies related to the } \\
\text { collection of VAT. The essence of the } \\
\text { Project is to create a decentralized } \\
\text { database that allows you to instantly } \\
\text { track the chain of financial } \\
\text { transactions of taxpayers and make } \\
\text { them a guaranteed VAT refund. }\end{array}$ & January 2019. \\
\hline 3 & Electronic invoices (ESF) & $\begin{array}{l}\text { allows you to issue and exchange } \\
\text { invoices in electronic form between } \\
\text { participants of trading operations in } \\
\text { real time }\end{array}$ & January 2019. \\
\hline
\end{tabular}

The digital age is changing everything: the nature of markets and products, ways of production, ways of delivery and payment, the scale of capital for global operations, and the requirements for human capital. It also improves productivity, introduces companies to new ideas, technologies, new management and business models, and creates new channels of market access. And all this at a relatively low cost. It is not an exaggeration to predict that firms will increasingly rely on artificial intelligence for basic procedures and for more complex tasks [11].

The vast majority of accounting professionals use data from the world wide web to more effectively keep records and find out what was unknown in a matter of minutes. Now the accountant does not need to wait for the next issue of the magazine, which reflects the innovations related to accounting, just $\log$ in And immediately see the updates, which simplifies the work and frees up time for the most important things than re-reading the magazines [12].

Previously, the work of accountants and financial specialists required that they mainly collect and update data, make reports, and perform Bank checks, accounting, and other tasks. Now, an accountant needs to keep up with the development of the digital economy, be digitally literate and constantly improve their skills not only professionally, but also in IT and information technologies. 
In accordance with the state program «Digital Kazakhstan», a target indicator is provided for increasing the level of digital literacy of the population to $83 \%$ by 2022 .

Digital literacy is the knowledge and ability of a person to use information and communication technologies in their daily and professional activities.

Based on this, it can be predicted that with global digitalization, the process of collecting, processing and storing information in accounting and changes in the accountant's function will be transformed.

In this regard, the question arose about the prospects for the development of the accounting profession: whether it will gradually leave the labor market or start a new round in its development.

Looking at the growing growth of modernized multimedia networks and technologies, the digital revolution will create a new mindset that accounting professionals will have to adapt to. As artificial intelligence and robotic innovations grow, so do opportunities for the financial and accounting sector [13].

\section{Conclusion}

Today, when using smart technologies, whether online or via mobile devices, artificial intelligence, opportunities, and benefits seem limitless.

Artificial intelligence has a significant impact on the world of accounting and Finance. By saving time and money and providing information, AI-enabled accounting and Finance systems help Finance professionals and their companies stay competitive and attract the best employees and customers. Adding artificial intelligence to accounting operations will also improve quality, as errors will be reduced.

If a company providing accounting services wants to be competitive in local and foreign markets, it must follow global trends. Today, it is very easy to transfer accounting (at least most of it) to another country, to another continent. That's why we need to work more efficiently and offer new opportunities to our clients [14].

Robots, or, in other words, programs that process data, today not only simplify the work of an accountant, but also make it more interesting, because they take on the most uninteresting part of routine work - manual data entry. One of the main tasks of these programs, which is being intensively improved, is the processing of digital documents (scanned documents, electronic invoices, Bank statements). Accountants no longer enter data into accounting programs - this is done by robots [15].

The only problem is that so far these programs can not work completely independently there are errors that «people still have to detect. For example, the program may confuse the letter «o» and the number «zero», capital letter «i» and the number «one» or an uppercase «i» and small letter «l». But robots have the ability to learn, and databases are becoming more global, so it's only a matter of time before people are no longer needed to process such primary information.

Although machines will become the most valuable colleagues of professionals in the future, nothing will replace the emotional intelligence that people bring to work, and this includes the Finance and accounting sectors.

\section{$4 \quad$ References}

1. T.L.Mesenbourg, Measuring the Digital Economy, US Bureau of the Census, Suitland, MD. (2001) 
2. On approval Of the state program «Digital Kazakhstan» decree Of the Government of the Republic of Kazakhstan dated December 12, No. 827. (2017)

3. T. M. Odintsovo Accounting in the context of challenges of the digital economy and information society / / Vestnik IPB (Bulletin of professional accountants no. 3 P. 5-14.) (2019)

4. https://digitalkz.kz/projects/

5. A. S. Abelyan Innovative development of modernized processes in industry: dis. on competition the degree of doctor of economic Sciences. Rostov-on-don, (2015)

6. T. P. Karpova Directions of development of accounting in the digital economy, (2017)

7. S. B. Baimukhanova Theory and methodology of accounting. Life Sci J 11(7s):35-40 (2014)

8. T. P. Karpova Accounting management accounting of production: the concept of improvement: autoreferat dis. for the degree of doctor of Economics. Moscow, (2004)

9. T. M. Odintsova, O. V. Ruhr Development of types, objects and methods of accounting in the digital economy and information society Scientific and technical sheets of SPbSPU. Economics. Volume 11, No. 4, (2018)

10.How Blockchain Technology Will Impact Accounting. URL: https://www.dvphilippines.com/blog/how-blockchain-technology-will-impact-accounting 11. Nawarathna Banda. Digital Economy // Presentation. — January 2019. — 20 p.

12. M. Yu. Tsivenko Transformation of the accountant profession in the conditions of development of the «digital economy» / / Young scientist. - - No. 48. - Pp. 100-102 (2017) 13 S.B. Baimukhanova The role and importance of accounting information for providing economic stability and intensive economic growth. Life Sci J;11(4s):63-67, (2014)

14. A. Nurmagambetova, A. Dzhondelbaeva, S. Nurmagambetov, Risk management in the activity of financial institutions, in conditions of unstable economic development World Applied Sciences Journal (2013)

15. GAAP.RU Homepage, https://gaap.ru/news/155373/, last accessed (2018) 